\title{
Comparison of the Effect of Two HMG CoA Reductase Inhibitors on LDL Susceptibility to Oxidation
}

\author{
Vera Lúcia Portal, Emílio H. Moriguchi, José Luiz da Costa Vieira, Sadi Schio, Eduardo T. Mastalir, \\ Fabiana Buffé, Eleni Borges Bortolini, Ricardo Santalucia Brüch, Rubem Rodrigues
}

Porto Alegre, RS - Brazil

\begin{abstract}
Objective - To study the differences between fluvastatin and pravastatin regarding $L D L$ susceptibility to oxidation, plasma levels of total cholesterol (TC), $H D L-C$, $L D L-C$ and triglycerides $(T G)$ in hypercholesterolemic patients with established coronary heart disease (CHD).

Methods - A double-blind randomized parallel study was conducted that included 41 hypercholesterolemic outpatients with CHD treated at the Instituto de Cardiologia do Rio Grande do Sul. The inclusion criteria were $L D L-C$ above $100 \mathrm{mg} / \mathrm{dL}$ and triglycerides below $400 \mathrm{mg} /$ $d L$ based on 2 measures. After 4 weeks on a low cholesterol diet, those patients that fullfilled the inclusion criteria were randomized into 2 groups: the fluvastatin group (fluvastatin $40 \mathrm{mg} /$ day) and the pravastatin group (pravastatin $20 \mathrm{mg} /$ day), for 24 weeks of treatment. $L D L$ susceptibility to oxidation was analyzed with copperinduced production of conjugated dienes $\left(\mathrm{Cu}^{2+}\right)$ and water-soluble free radical initiator azo-bis (2'-2 amidinopropanil) $\mathrm{HCl}$ (AAPH). Spectroscopy nuclear magnetic resonance was used for determination of lipids.
\end{abstract}

Results - After 24 weeks of drug therapy, fluvastatin and pravastatin significantly reduced LDL susceptibility to oxidation as demonstrated by the reduced rate of oxidation (azo and $\mathrm{Cu}$ ) and by prolonged azo-induced lag time (azo lag). The TC, $L D L-C$, and TG reduced significantly and HDL-C increased significantly. No differences between the drugs were observed.

Conclusion - In hypercholesterolemic patients with CHD, both fluvastatin and pravastatin reduced LDL susceptibility to oxidation.

Keywords: LDL oxidation, statins, hypercholesterolemia

Instituto de Cardiologia do Rio Grande do Sul/Fundação Universitária de Cardiologia e Instituto de Geriatria da Pontifícia Universidade Católica do RS. Wake Forest University School of Medicine, Lipoprotein Laboratory. Winston Salem, North - Caroline, USA.

Mailing address: Vera Lúcia Portal - IC/FUC - Serviço de Epidemiologia - Av. Princesa Isabel, 395 - 90.620-001 - Porto Alegre, RS - Brasil -

E-mail: pesquisa@cardnet.tche.br
Atherosclerosis is a progressive and multifactorial inflammatory process involving a series of highly specific cellular and molecular responses that may lead to clinical coronary events, such as acute myocardial infarction, unstable angina, and sudden cardiac death ${ }^{1,2}$. A causal relationship between high cholesterol levels, especially high lowdensity lipoprotein cholesterol (LDL-C) levels, and coronary heart disease (CHD) is well established ${ }^{3-7}$. During the last years, a developing set of evidences demonstrated that low-density lipoproteins (LDL) particle oxidation has an important role in the pathogenesis of atherosclerosis ${ }^{1,8-12}$. Experimental in vitro and in vivo studies show that an isolated increase in LDL-C levels by itself would not totally explain all processes associated with atherogenesis ${ }^{13-17}$. Oxidative modification undergone by LDL particles in the vessel intima would prepare the particle for uptake by macrophages, leading to the formation of foam cells ${ }^{18-20}$, the first step in the formation of early lesions in the pathogenesis of atherosclerosis ${ }^{21,22}$.

It is believed that part of the beneficial effect obtained through the use of statins in the reduction of cardiovascular events ${ }^{3-7}$, in addition to LDL-C reduction effects, could be due to its antioxidant action adding an antiatherogenic effect ${ }^{23-39}$.

For that reason, we conducted a randomized study to evaluate the antioxidant action of 2 statins, fluvastatin and pravastatin, used in clinical practice as lipid-lowering drugs to test the hypothesis that these drugs reduce LDL susceptibility to oxidation.

\section{Methods}

The study was undertaken between July 1998 and June 1999 at the Instituto de Cardiologia do Rio Grande do Sul. The protocol was approved by the institutional review board. All patients gave written informed consent.

Potential subjects comprised 258 hypercholesterolemic outpatients of both sexes, with angiographically documented CHD, ages between 35 and 75 years. From this po- 
pulation, 45 elegible consecutive patients were included in the study according to inclusion and exclusion criteria described below.

According to the established inclusion criteria, only patients fulfilling the following requirements could be included in the study: LDL-cholesterol (LDL-C) above $100 \mathrm{mg} / \mathrm{dL}$ (more than 2 measurements); triglycerides below $400 \mathrm{mg} / \mathrm{dL}$; diabetic patients needed to be well-controlled with stable plasma glucose levels, eg, a fasting glucose level below 110 $\mathrm{mg} / \mathrm{dL}$ during at least 3 consecutive months.

All 45 patients received orientation to proceed with the American Heart Association Step II (NCEP - ATP II) diet to be followed throughout the study. After the first 4 weeks on the diet, the 41 patients who still had LDL-C above 100 $\mathrm{mg} / \mathrm{dL}$ were randomized into 2 groups in a double-blind mode: 1 group received $40 \mathrm{mg}$ /day of fluvastatin (fluvastatin group) and the other $20 \mathrm{mg} /$ day of pravastatin (pravastatin group). The follow-up period was 24 weeks, with patient examination at intervals of 4 weeks. If after a 4-week period from the start of drug treatment the LDL-C was still above $100 \mathrm{mg} / \mathrm{dL}$, the drug dosage was doubled at the next visit. At each follow-up visit, study staff provided counseling regarding adherence to the study regimen and using a standard questionnaire asked about the occurrence of any relevant events and side-effects after the previous visit.

Exclusion criteria were secondary hyperlipidemia; a history of acute myocardial infarction or stroke occurring within the previous 3 months; severe cardiac failure (NYHA class III or IV); acute atrial fibrillation; alcohol dependance; hepatic disease (transaminases or bilirubins levels more than 2 times the normal level); renal disease (creatinine $>1.5$ $\mathrm{mg} / \mathrm{dL}$ ); chronic pancreatitis; systemic lupus erythematosus; porphyria; severe gastrointestinal disease; morbid obesity (>140\% ideal body weight); use of drugs, such as hormones other than postmenopausal hormone reposition, immunosuppressants, statins, nicotinic acid, resins, or both, in the last 8 weeks and probucol, fibrates, or both, in the last 12 weeks.

Arterial blood pressure was measured with patients in the sitting position after at least 5 minutes of rest, with a previously calibrated Tycos anaeroid sphygmomanometer. Patients with hypertension were considered those taking antihypertensive medication or having mean pressure levels above $140 / 90 \mathrm{mmHg}$ in at least 2 pressure monitorings.

Patients considered diabetic were those who identified themselves as such, were using hypoglycemic medication, or had fasting serum glucose concentrations above $126 \mathrm{mg} / \mathrm{dL}$ in 2 readings.

Body mass index (BMI) was calculated with the ratio body weight (in kilograms)/square height (in meters). Patients were classified as current smokers, past smokers, and nonsmokers. In the statistical analysis of baseline characteristics, the only percentage considered was that of current smokers. Patients were asked about alcohol abuse. Sedentary patients were those who practiced some sort of physical activity less than 3 times a week and for less than 30 minutes per session ${ }^{41}$.
Blood samples were collected at 4-weeks intervals, after the patient fasted overnight for 12 hours, and were immediately centrifuged for 15 minutes at $1,600 \mathrm{G}$ for plasma collection. Levels of glucose, alanine aminotransferase (ALT), urea (BUN), creatinine and total proteins, and thyrotropin hormone were measured, and prothrombin time estimation, activated partial thromboplastin time (APTT), fibrinogen, and blood sample analysis and blood platelet count were determined immediately after blood was collected at the laboratory of the Instituto de Cardiologia do Rio Grande do Sul, in Porto Alegre. Glucose, ALT, creatine kinase (CK), urea, creatinine, and total proteins were measured with commercially available kits (Merck Diagnostics). Thyrotropin hormone was evaluated by polarized fluorescence with Opus of Dade and Boehringer Equipment. Blood sample and platelets were analyzed with an automatic counter, model 818 by AVL. Fibrinogen, prothrombin time, and APTT were evaluated on Dade Boehringer's Fibrintimer II.

The remaining plasma was placed in a polypropylene vial, which was placed under nitrogen flow before being closed with a silicone screw cap to avoid plasma contact with oxygen, to determine LDL susceptibility to oxidation. Samples were stored in boxes containing dry ice (between $0^{\circ}$ and $4^{\circ} \mathrm{C}$ ) and sent to the Lipoproteins-Laboratory of Wake Forest University School of Medicine, WinstonSalem, North Carolina, United States less than 24 hours after collection. Additional plasma samples were frozen at $75^{\circ} \mathrm{C}$ for later lipid analysis at the same laboratory.

Lipid determination was accomplished with a Bruker WM 250 spectrometer, with a recently validated spectroscopy method that uses proton magnetic nuclear resonance (MNR), which has become a more precise, rapid, and less costly alternative in relation to previously existing methods for the dosage of lipoprotein subfractions ${ }^{42-44}$. The basis of analysis with this method rests on the fact that each lipoprotein particle, within a diameter band, "irradiates" a distinct MNR sign that is proportional to the total lipid mass concentration.

LDL susceptibility to oxidation was evaluated with 2 methods. One was by the formation of conjugated dienes induced by copper $\left(\mathrm{Cu}^{+2}\right)$. In short, the heparinized fresh plasma was treated with G-25 gel filtration with the rapid column centrifugation technique to remove antioxidants soluble in water. LDL was separated from plasma by ultracentrifugation with a gradient of discontinued density in a vertical column. The isolated LDL was dialyzed overnight at $4^{\circ} \mathrm{C}$ against a $25-\mathrm{mM}$ phosphate buffer, $\mathrm{pH} 7.2$, and $0.1 \mathrm{M}$ $\mathrm{NaCl}$. The LDL (100 mg protein $/ \mathrm{mL}$ ) was then incubated in the presence of $10 \mu \mathrm{M} \mathrm{CuSO}_{4}$ at $37^{\circ} \mathrm{C}$. LDL oxidation kinetics was continuously monitored by measuring the conjugated diene formation, with the increase in absorbancy at $234 \mathrm{~nm}$. Absorbancy was analyzed at 10-minute intervals. The presentation of results is figured by the lag phase (reflecting the resistance of LDL to oxidation, measured in minutes) directly related to the amount of antioxidant carried by the LDL, and the rate phase (rate of action/velocity of LDL particle oxidation, measured in mol. $\mathrm{mol}^{-1} \cdot \mathrm{min}^{-1}$ ), 
depending on the LDL particle concentration and on the amount of polyunsaturated fatty acids (PUFA) carried by LDL. A longer lag phase demonstrates a reduced susceptibility of LDL particles to oxidation, caused by a higher antioxidant concentration, whereas a shorter lag phase means that LDL particles take less time to oxidize, due to the lower presence of antioxidants ${ }^{45-47}$.

The other method of LDL oxidation evaluation was by particle incubation with $5 \mathrm{mM}$ of AAPH (2'-2' amidinopropanil hydrochloride- azo), for $4 \mathrm{~h}$, at $37^{\circ} \mathrm{C}$. AAPH is a free radical generator system that decomposes thermically and generates water-soluble peroxyl radicals at a constant rate. Plasma samples were analyzed as for their oxidation conditions, at the end of the incubation period, by using thiobarbituric acid reactive substances (TBARS) to which equivalent amounts of malondialdehyde were measured. Lipidic peroxidation was calculated subtracting the obtained values in the absence of AAPH from those obtained in the presence of AAPH. Results were also presented in the form of phase lag and rate ${ }^{45-47}$.

Values of $p<0.05$ in the 2-tailed test were considered significant. Baseline differences between the groups in relation to demographic and biochemical variables were analyzed with the Student $t$ test for independent samples, in the case of continuous variables, and by the chi-square test for categoric variables. Variations throughout the period of treatment of lipid levels, ie, TC, LDL-C, HDL-C, and TG, as well as measure evaluations of LDL susceptibility to oxidation, ie, Cu rate, Azo rate, Cu lag, and Azo lag, were evaluated within each group and between both groups by the factorial analysis of variance (ANOVA), with the TukeyKramer localization test being used, when necessary.

\section{Results}

The study was concluded with 39 patients. Approximately $60 \%$ of them needed a dosage of $40 \mathrm{mg} /$ day of pravastatin or $80 \mathrm{mg} /$ day of fluvastatin to reach the target level of the study of LDL $<100 \mathrm{mg} / \mathrm{dL}$. Of the 41 randomized patients, one was excluded because of adverse gastrointestinal effects (fluvastatin group), and the other patient withdrew for no specific reason (pravastatin group). Adherence to treatment measured by counting the remaining tablets was $97 \%$ in the fluvastatin group and $96 \%$ in the pravastatin group.

The baseline characteristics of the 2 randomized groups (fluvastatin and pravastatin) are summarized in table I. No significant differences occurred between the groups in relation to demographic characteristics, previous myocardial infarction history, number of coronary vessels with lesions, the presence of coronary risk factors, lipid levels, and use of medications (tab. I).

Results of mean plasma levels of TC, LDL-C, HDL-C, and TG at baseline and the 24th week are presented in table II. A significant decrease was seen in TC, LDL-C, and TG levels and a significant increase in HDL-C by the end of treatment period. The fluvastatin group had $18 \%$ lower TC,

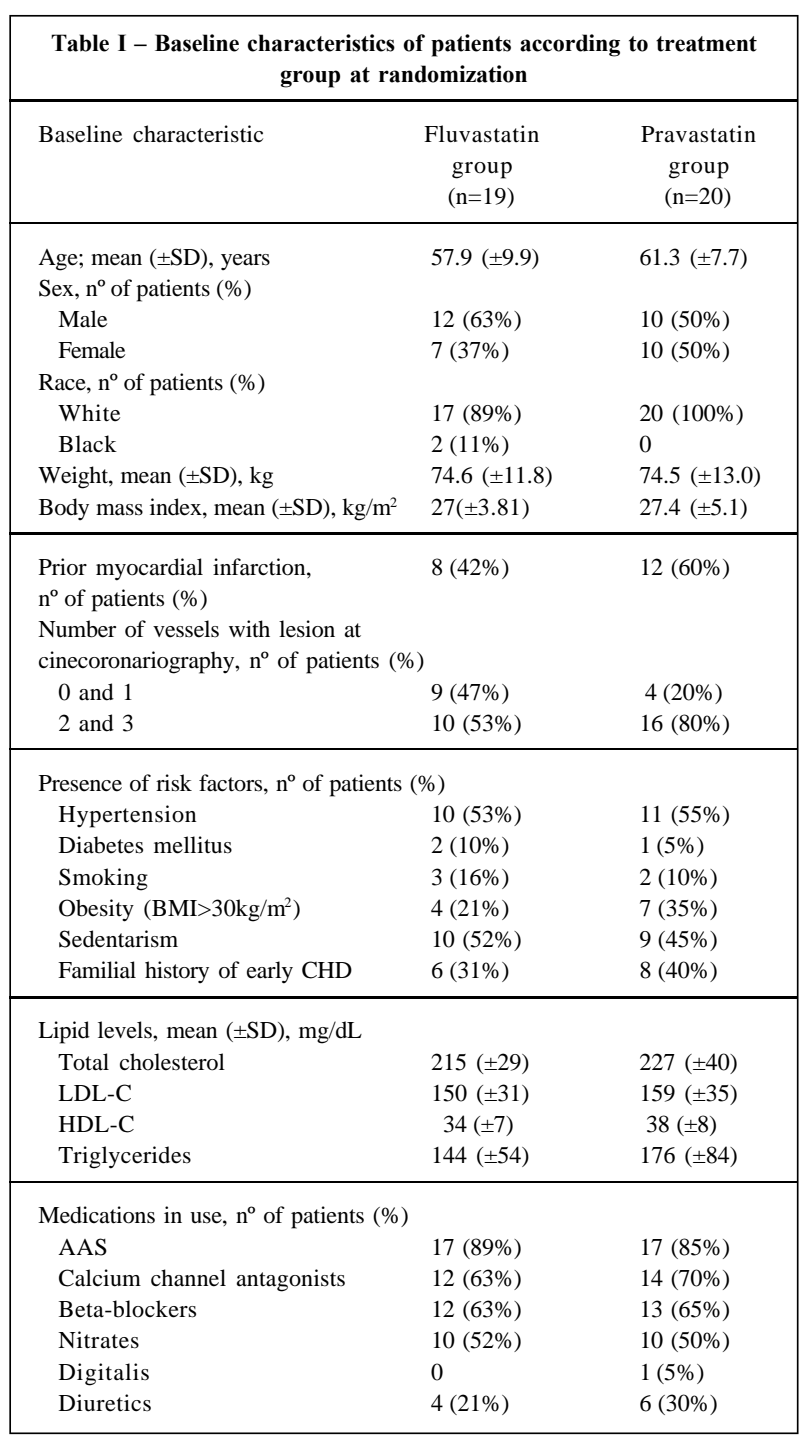

$25 \%$ lower LDL-C, and 13\% lower triglycerides plasma levels and an $11 \%$ increase in HDL-C levels, whereas the pravastatin group had reductions of $21 \%$ in TC, $25 \%$ in LDL$\mathrm{C}$, and $37 \%$ in triglycerides levels, and a $10 \%$ increase in HDL-C (tab. II).

The results of LDL susceptibility to oxidation throughout the study are presented in table III and figures 1 through 4 . The LDL susceptibility to oxidation decreased after the use of either drug. When the susceptibility to oxidation was evaluated by the rate of oxidation catalyzed by $\mathrm{Cu}^{+2}$ (Cu rate), a 24\% reduction was observed in the fluvastatin group and a $26 \%$ reduction in the pravastatin group, and using the oxidation initiator AAPH (Azo rate), a $48 \%$ reduction occurred in both groups.

When the LDL susceptibility to oxidation was evaluated with the lag time duration using initiator AAPH as the catalyzer (Azo lag), an increase of $17 \%$ and $24 \%$ was demonstrated respectively in fluvastatin and pravastatin groups. No difference was seen in either group when $\mathrm{Cu}^{+2}$ was used (Cu lag). In all these measurements, no difference was seen between the 2 drugs (tab. III) (fig. 1-4). 


\begin{tabular}{|c|c|c|c|c|c|c|}
\hline \multirow{2}{*}{$\begin{array}{l}\text { Mean Plasma } \\
\text { Level }\end{array}$} & \multicolumn{2}{|c|}{ Fluvastatin } & \multicolumn{2}{|c|}{ Pravastatin } & \multirow{2}{*}{$\begin{array}{l}\mathrm{p} \text { of therapy } \\
\text { effect }^{2}\end{array}$} & \multirow{2}{*}{$\begin{array}{l}\mathrm{p} \text { of therapy } \\
\text { difference }^{3}\end{array}$} \\
\hline & Week.0 & Week.24 & Week.0 & Week.24 & & \\
\hline $\mathrm{TC}$ & $215 \pm 29$ & $175 \pm 21$ & $227 \pm 40$ & $180 \pm 33$ & $<0.0001^{*}$ & 0.39 \\
\hline LDL-C & $150 \pm 36$ & $112 \pm 21$ & $159 \pm 35$ & $119 \pm 26$ & $<0.0001^{*}$ & 0.50 \\
\hline HDL-C & $35 \pm 7$ & $39 \pm 8$ & $38 \pm 8$ & $41 \pm 9$ & $<0.02^{*}$ & 0.10 \\
\hline TG & $144 \pm 54$ & $126 \pm 39$ & $176 \pm 84$ & $111 \pm 44$ & $<0.008^{*}$ & 0.51 \\
\hline
\end{tabular}

Both fluvastatin and pravastatin demonstrated good tolerability and safety. The most frequently observed adverse events were those related to the gastrointestinal tract (2.5\%), sim ilarto thosereported in the literature ${ }^{48-51}$.

\section{Discussion}

A body of randomized clinical studies has consistently demonstrated that reduction in LDL-C levels, through the use of statins, decreases coronary events ${ }^{3-7}$, cardiovascular mortality ${ }^{3-7}$, and total mortality ${ }^{3-6}$. On the other hand, in vitro ${ }^{13-15}$ and in vivo ${ }^{16-17}$ experimental studies show that the isolated increase in LDL levels by itself would not explain all processes related to atherogenesis. Possibly, oxidative modifications undergone by the particle inside the vessel intima would target it for uptake by the macrophages that will result in foam cells ${ }^{18-20}$, the first step in the formation of early lesions in the pathogenesis of atherosclerosis ${ }^{21-22}$. It is considered that part of the favorable effect obtained with statins in the reduction of cardiovascular events, besides LDL-C reduction effects, could be due to its antioxidant action, adding an antiatherogenic effect ${ }^{37-40,48}$.

In this randomized, double-blind clinical trial, 2 statins were used and although both of them have the same mechanism of action for reducing cholesterol levels through the inhibition of HMG CoA reductase, they have distinct chemical structures and different metabolites ${ }^{52}$, which could make them different regarding their antioxidant effects ${ }^{24}$.

This study evaluated LDL susceptibility to oxidation through the formation of copper-induced conjugated dienes $\left(\mathrm{Cu}^{+2}\right)$, with an increase in absorbancy at $234 \mathrm{~nm}$, and of AAPH (azo) induced conjugated dienes, a generator system of peroxyl radicals. They are simple, provide reproducible

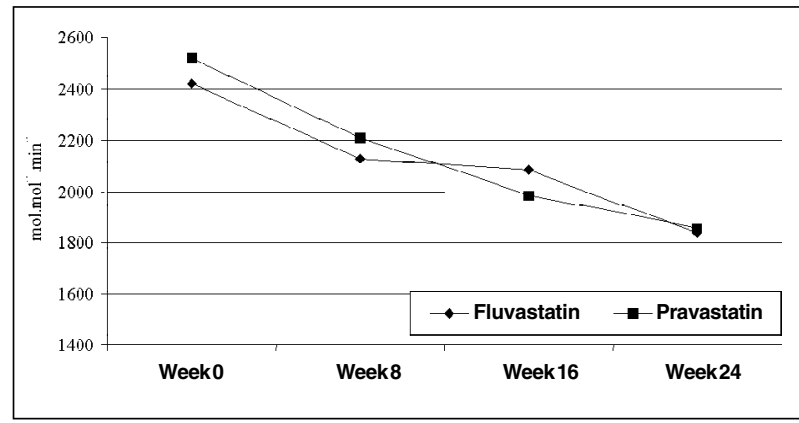

Fig. 1 - LDL oxidation rate catalyzed by $\mathrm{Cu}^{+2}(\mathrm{Cu}$ rate $)$ in both groups throughout the study.

results within a short period, do not require sophisticated equipment, and can be semiautomated for routine clinical use ${ }^{53}$.

The results are presented as lag time and rate of oxidation (fig. 1-4). After 24 weeks of active therapy, LDL particles' tendency toward oxidation was reduced by both drugs as demonstrated by the increase in Azo lag and by the decrease in Azo rate and Cu rate. The lag phase, when LDL autoxidation was catalyzed by copper ( $\mathrm{Cu} \mathrm{lag})$, did not show significant differences regarding the 2 study drugs.

The lag phase for both drugs, when autoxidation was copper catalyzed, did not show statistically significant antioxidant effects. However, a few studies, including that published by Thomas et al ${ }^{46}$ pointed out that although the lag phase should be considered the most relevant parameter of LDL susceptibility to oxidation, when the autoxidation was copper catalyzed, the results can be misleading. These studies showed that the correlation between the lag phase and the amount of $\alpha$-tocopherol carried by individuals' LDLs $^{46,47}$ was more evident with the azo system.

\begin{tabular}{|c|c|c|c|c|c|c|}
\hline \multicolumn{7}{|c|}{ Table III - LDL susceptibility to oxidation catalyzed by $\mathrm{Cu}^{+2}$ and by AAPH' (Azo) in both groups } \\
\hline \multirow[t]{2}{*}{ Oxidation Test } & \multicolumn{2}{|c|}{ Fluvastatin } & \multicolumn{2}{|c|}{ Pravastatin } & \multirow{2}{*}{$\begin{array}{c}* \mathrm{p} \text { of treatment } \\
\text { effect }^{2}\end{array}$} & \multirow{2}{*}{$\begin{array}{c}\text { p of difference } \\
\text { between therapies }\end{array}$} \\
\hline & Week 0 & Week 24 & Week 0 & Week 24 & & \\
\hline $\mathrm{Cu}$ rate ${ }^{4}$ & $2422( \pm 752)$ & $1836( \pm 425)$ & $2522( \pm 650)$ & $1857( \pm 309)$ & $<0.0001^{*}$ & 0.93 \\
\hline Azo rate ${ }^{4}$ & $438( \pm 185)$ & $228( \pm 113)$ & $412( \pm 162)$ & $214( \pm 105)$ & $<0.0001^{*}$ & 0.69 \\
\hline $\mathrm{Cu}$ lag ${ }^{5}$ & $48 \quad( \pm 18)$ & $50 \quad( \pm 15)$ & $42( \pm 13)$ & $46 \quad( \pm 17)$ & $<0.02^{*}$ & 0.18 \\
\hline Azo lag 5 & $54 \quad( \pm 14)$ & $63( \pm 13)$ & $53( \pm 13)$ & $66 \quad( \pm 16)$ & $<0.008^{*}$ & 0.22 \\
\hline
\end{tabular}




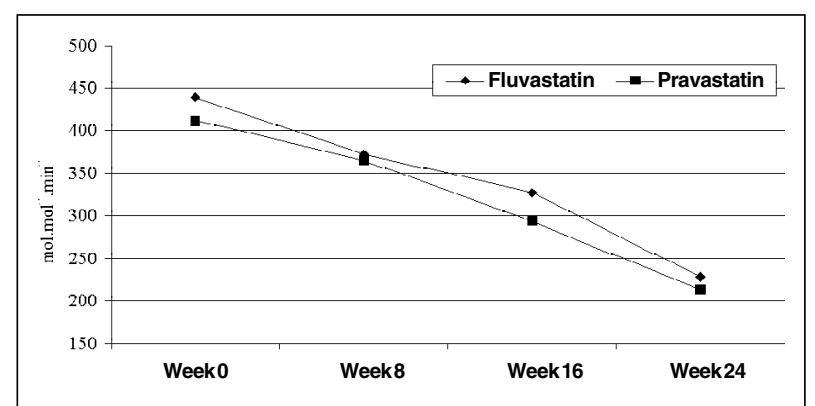

Fig. 2 - LDL oxidation rate catalyzed by AAPH (Azo rate) in both groups throughout the study.

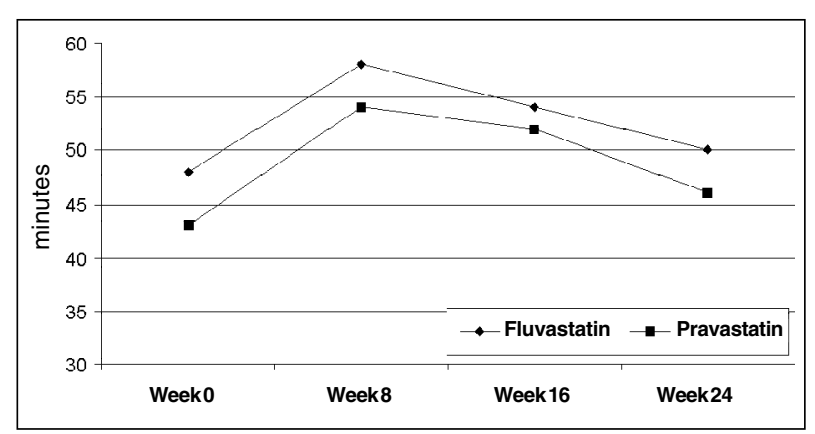

Fig. 3 - Lag time for LDL oxidation catalyzed by $\mathrm{Cu}^{+2}(\mathrm{Cu}$ lag) in both groups throughout the study.

We did not find any statistically significant difference between the 2 drugs in relation to their antioxidant effects. In a literature review, we noted that in studies of Suzumura et al ${ }^{29}$ and in Yasuhara et al ${ }^{31}$, it was demonstrated that fluvastatin was superior to pravastatin. On the other hand, Kleinveld et al ${ }^{35}$ compared pravastatin's effects with those of simvastatin in in vitro LDL oxidation and did not find any significant difference between the drugs.

It is well demonstrated that the PUFA content of LDL particles influences their susceptibility to oxidation. The PUFA content of lipoproteins depends basically on the $\operatorname{diet}^{45,47}$. Although we had not measured the PUFA content of LDL, the standard dietary treatment given to all patients, by the same nutritionist, since weeks before and during all the pharmacological treatment, would allow us to deduce that the PUFA content of LDL had not changed during statins treatment.

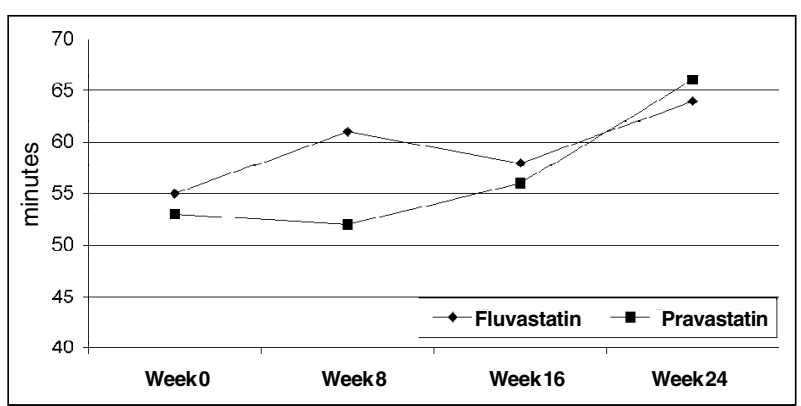

Fig. 4 - Lag time for LDL oxidation catalyzed by AAPH (Azo lag) in both groups throughout the study.

The lag phase elevation and the rate of reduction after fluvastatin and pravastatin treatment were probably due to antioxidant properties of the 2 drugs and their metabolites ${ }^{33}$ and not secondary to modifications in the fatty acid composition of particles ${ }^{28}$.

Our results showed that fluvastatin and pravastatin significantly reduced LDL-C levels and LDL susceptibility to oxidation, with no significant difference between drugs in relation to such effects.

Both drugs reduced LDL-C by $25 \%$ and increased serum levels of HDL-C by $10 \%$ and $11 \%$, with no difference between them. In relation to triglycerides, we found a decrease of $13 \%$ in the fluvastatin group and of $37 \%$ in the pravastatin group. We believe that this difference in triglyceride level changes, although not significant, might be a consequence of no homogeneity between the groups because a major values dispersion has occurred in the pravastatin group. Another possibility to be considered in the explanation of our results is that baseline levels of triglycerides in the pravastatin group were $22 \%$ above that in the fluvastatin group.

Concluding, our results showed that fluvastatin and pravastatin significantly reduced LDL-C levels and LDL susceptibility to oxidation, with no significant difference between drugs in relation to such effects. Because they are drugs with different chemical structures and metabolites, one may conclude that in addition to the effects on plasma levels of LDL-C, these 2 HMG CoA reductase inhibitors have antioxidant effects that may be linked to coronary protection.

\section{References}

1. Ross R. The pathogenesis of atherosclerosis: a perspective for the 1990s. Nature 1993; 362: 801-09.

2. Ross R. Mechanisms of disease: atherosclerosis - an inflammatory disease. $\mathrm{N}$ Engl J Med 1999; 340: 1-10.

3. Pedersen TR, Kjekshus J, Berg K, et al. Randomised trial of cholesterol lowering in 4444 pacients with coronary heart disease: the Scandinavian Simvastatin Survival Study (4S). Lancet 1994; 344: 1383-9.

4. SacksFM,Pfeffer MA, Move LA, et al. The effect of pravastatin on coronary events after myocardial infarction in patients with average cholesterol levels: the Cholesterol and Recurrent Events Trial (CARE). N Engl J Med 1996; 335: 1001-9.
5. The Long-Term Intervention with Pravastatin in Ischaemic Disease (LIPID) Study Group. Prevention of cardiovascular events and death with pravastatin in patients with coronary heart disease and a broad range of initial cholesterol levels. N Engl J Med 1998; 339: 1349-57.

6. Shepherd J, Cobbe SM, Ford I, et al. Prevention of coronary heart disease with pravastatin in men with hypercholesterolemia: the West Of Scotland Coronary Prevention Study (WOSCOPS). N Engl J Med 1995; 333: 1301-07.

7. Downs JR, Clearfield M, Weis S, et al. Primary prevention of acute coronary events with lovastatin in men and women with average cholesterol levels: results of AFCAPS/TexCAPS. JAMA 1998;279:1615-22. 
8. Libby P. Molecular bases of the acute coronary syndromes. Circulation 1995; 91 : 2844-50.

9. Gofman JW, Dellala O, Glazier F, et al. The serum lipoprotein transport system in health, metabolic disorders, atherosclerosis and coronary artery disease. Plasma 1954; 2: 414-84. Apud Steinberg D, Gotto AM. Preventing coronary artery disease by lowering cholesterol levels: fifty years from bench to bedside. JAMA 1999; 282: 2-9.

10. Rhoads G, Gulbrandsen C, Kagan A. Serum lipoproteins and coronary heart disease in a population study of Hawaii Japonese men. N Eng J Med 1976; 294: 293-8.

11. Prevention of coronary heart disease in clinical practice: recommendations of the Second Joint Task Force of European and Other Societies on Coronary Prevention. Eur Heart J 1998; 19: 1434-503.

12. Ross R. The Pathogenesis of Atherosclerosis. In: Braunwald E (Ed.). Heart Disease. A Textbook of Cardiovascular Medicine. New York: W.B. Saunders, 1997: 1105-25.

13. Buja LM, Kita T, Goldstein JL, Watanabe Y, Brown MS. Cellular pathology of progressive atherosclerosis in the WHHL rabbit: an animal model of hypercholesterolemia. Arteriosclerosis 1983; 3: 87-101.

14. Heinecke JW, Rosen H, Chait A. Iron and copper promote modification of low density lipoprotein by human arterial smooth muscle cells in culture. J Clin Invest 1984; 74: 1890-94.

15. Morel DW, DiCorleto PE, Chisolm GM. Endothelial and smooth muscle cells alter low density lipoprotein in vitro by free radical oxidation. Atherosclerosis 1984; 4: 357-64.

16. Haberland ME, Fong D, Cheng L. Malondialdehyde-altered protein occurs in atheroma of Watanabe heritable hyperlipidemic rabbits. Science 1988; 241: 215-8.

17. Palinski W, Rosenfeld ME, Yla-Herttuala S, et al. Low density lipoprotein undergoes oxidative modification in vivo. Proc Natl Acad Sci USA 1989; 86 1372-6.

18. Cathcart MK, Morel DW, Chisolm GM III. Monocytes and neutrophils oxidize low-density lipoproteins making it cytotoxic. J Leukoc Biol 1985; 38: 341-50.

19. Parthasarathy S, Printz DJ, Boyd D, Joy L, Steinberg D. Macrophage oxidation of low dendity lipoprotein generates a modified form recognized by the scavenger receptor. Arteriosclerosis 1986; 6: 505-10.

20. Hiramatsu K, Rosen H, Heinecke, JW, Wolfbauer G, Chait A. Superoxide initiates oxidation of low-density lipoprotein by human monocytes. Arteriosclerosis 1987; 7: 55-60.

21. Gerrity RG. The role of the monocyte in atherogenesis. II. Migration of foam cells from atherosclerotic lesions. Am J Pathol 1981; 103: 191-200.

22. Faggiotto A, Ross R. Studies of hypercholesterolemia in the nonhuman primate. I. Changes that lead to fatty streak formation. Arteriosclerosis 1984; 4: 323-56.

23. Chen L, Haught WH, Yang B, et al. Preservation of endogenous antioxidant activity and inhibition of lipid peroxidation as common mechanisms of antiatherosclerotic effects of vitamin E, lovastatin and amlodipine. J Am Coll Cardiol 1997; 30: 569-75.

24. Giroux LM, Davignon J, Naruszewicz M. Simvastatin inhibits the oxidation of low density lipoproteins by activated human monocyte-derived macrophages. Biochim Biophys Acta Lipids Lipid Metab 1993; 1165: 335-8.

25. Aviram M, Dankner C, Cogan U, et al. Lovastatin inhibits LDL oxidation and alters its fluidity and uptake by macrophages: in vitro and in vivo studies. Metabolism 1992; 41: 229-35.

26. Kimura M, Kurose I, Russell J, Granger DN. Effects of fluvastatin on leukocyteendothelial cell adhesion in hypercholesterolemic rats. Arterioscler Thromb Vasc Biol 1997; 17: 11521-6.

27. Weber C, Erl W, Weber KSC, Weber PC. HMG CoA reductase inhibitors decrease $\mathrm{CD} 11 \mathrm{~b}$ expression and CD11b-dependent adhesion of monocytes to endothelium and reduce increased adhesiveness of monocytes isolated from patients with hypercholesterolemia. J Am Coll Cardiol 1997; 30: 1212-17.

28. Hussein O, Schlezinger S, Rosenblat M, Keidar S, Aviram M. Reduced susceptibility of low density lipoprotein (LDL) to lipid peroxidation after fluvastatin therapy is associated with the hypocholesterolemic effect of the drug and its binding to the LDL. Atherosclerosis 1997; 128: 11-8.
29. Suzumura K, Yasuhara M, Tanaka K, Odawara A, Narita H, Suzuki T. Na in vitro of the hydroxyl radical scavenging property of fluvastatin, and HMG CoA reductase inhibitor. Chem Pharm Bull 1999; 47: 1010-2.

30. Suzumura K, Yasuhara M, Tanaka K, Suzuki T. Protective effect of fluvastatin sodium (XU-62-320), a 3-hydroxy-3-methylglutaryl coenzyme a (HMG CoA) reductase inhibitor, on oxidative modification of human low-density lipoprotein in vitro. Biochem Pharmacol 1999; 57: 697-703.

31. Yasuhara M, Suzumura K, Tanaka K, et al. Fluvastatin, na HMG CoA reductase inhibitor, protects LDL from oxidative modification in hypercholesterolemic rabbits. Biol Pharm Bull 2000; 23: 570-4.

32. Blaha V, Zadak Z, Solichova D, Bratova M, Havel E. Hypocholesterolemic effect of pravastatin is associated with increased content of antioxidant vitamin-E in cholesterol fractions. Acta Medica (Hradec Kralove) 1998; 41: 87-90.

33. Nakashima A, Ohtawa M, Masuda N, Morikawa H, Bando T. Antioxidative effects of fluvastatin, and its major metabolites. Yakugaku Zasshi 1999; 19: 93-9.

34. Aviram M, Rosenblat M, Bisgaier CL, Newton RS. Atorvastatin and gemfibrozil metabolites, but not the parent drugs, are potent antioxidants against lipoprotein oxidation. Atherosclerosis 1998; 138: 271-80.

35. Kleinveld HA, Demacker PNM, De Haan AFJ, Stalenhoef AFH. Decreased in vitro oxidizability of low-density lipoprotein in hypercholesterolemic patients treated with 3-hydroxy-3-methylglutaryl-CoA reductase inhibitors. Eur J Clin Invest 1993; 23: 289-95.

36. Leonhardt W, Kurktschiev D, Meissner P, et al. Effects of fluvastatin therapy on lipids, antioxidants, oxidation of low density lipoproteins and trace metals. Eur Clin Pharmacol 1997; 53: 65-9.

37. Steinberg D, Lewis A. Conner Memorial Lecture. Oxidative Modification of LDL and Atherogenesis. Circulation 1997; 95: 1062-71.

38. Steinberg D, Gotto AM. Preventing coronary artery disease by lowering cholesterol levels: fifty years from bench to bedside. JAMA 1999; 282: 2-9.

39. Blumenthal RS. Statins: Effective antiatherosclerotic therapy. Am Heart J 2000; 139: 577-83.

40. Vaughan CJ, Gotto Jr AM, Basson CT. O papel cada vez maior das estatinas no tratamento da aterosclerose. J Am Col Cardiol 2000; 35: 1-10.

41. American College Sports Medicine. ACSM's Guidelines for Exercise Testing and Prescription. Baltimore: Williams \& Wilkins, 1995.

42. Otvos JD. Measurement of lipoprotein subclass profiles by NMR spectroscopy. In: Rifai N, Warnick R, Dominiczak M, eds. Handbook of Lipoprotein Testing. Washington DC: AACC Press, 1997: 497-508.

43. Otvos J. Measurement of triglyceride-rich lipoprotein by NMR spectroscopy. Clin Cardiol 1999; 22: 21-27.

44. Otvos JD, Jeyarajah EJ, Bennett D. A spectroscopic approach to lipoprotein subclass analysis. J Clin Ligand Assay 1996; 19: 184-9.

45. Thomas MJ, Thornburg T, Manning J, et al. Fatty acid composition of lowd-density lipoprotein inflences its suscetibility to autoxidation. Biochemistry 1994; 33: $1828-34$.

46. Thomas MJ, Chen Q, Franklin C, Rudel LL. A comparison of the kinetics of lowdensity lipoprotein oxidation initiated by copper or by azobis (2-amidinopropane). Free Radical Biology \& Medicine 1997; 23: 927-35.

47. Thomas MJ, Rudel LL. Dietary fatty acids, low density lipoprotein composition and oxidation and primate atherosclerosis. J Nutr 1996; 126: 1058S-62S .

48. Maron DJ, Fazio S, Linton MF. Current perspectives on statins. Circulation 2000; 101: 207-13.

49. Jones P, Kafonek S, Laurora I, et al. Comparative dose efficacy study of atorvastatin versus simvastatin, pravastatin, lovastatin, and fluvastatin in patients with hypwercholesterolemia (the CURVES study). Am J Cardiol 1998; 81: 582-7.

50. McTavish D, Sorkin EM. Pravastatin: a review of its pharmacological properties and therapeutic potential in hypercholesterolaemia. Drugs 1991; 42: 65-9.

51. Plosker GL, Wagstaff AJ. Fluvastatin: a review of its pharmacology and use in the management of hypercholesterolaemia. Drugs 1996; 51: 433-59.

52. Endo A. The discovery and development of HMG CoA reductase inhibitors. J Lipid Res 1992; 33: 1569-82.

53. Stocker R. Lipoprotein oxidation: mechanistic aspects, tethodological approaches and clinical relevance. Curr Opin Lipidol 1994; 5: 422-33. 